Computer Optics and Nanophotonics

\title{
FOR THE ANNIVERSARY OF PROFESSOR L.L. DOSKOLOVICH
}

\author{
E.I. Kolomiets
}

Samara National Research University, Samara, Russia

\begin{abstract}
The article briefly describes the scientific and pedagogical achievements of Professor, Doctor of Physical and Mathematical Sciences, Leonid L. Doskolovich.
\end{abstract}

Keywords: diffractive optics, diffraction grating, resonant photonic structure, nonimaging optics.

Citation: Kolomiets EI. For the anniversary of professor L.L. Doskolovich. CEUR Workshop Proceedings, 2016; 1638: 226-235. DOI: 10.18287/16130073-2016-1638-226-235

\section{Introduction}

In January, 2016 Doctor of Physical and Mathematical Sciences, Head of the laboratory of diffractive optics of the Image Processing Systems Institute - Branch of the Federal Scientific Research Center "Crystallography and Photonics" of Russian Academy of Sciences (IPSI RAS), and professor of the Department of technical cybernetics of Samara national research University named after academician Sergey Korolev, Leonid Leonidovich Doskolovich celebrated his $50^{\text {th }}$ anniversary. The article summarizes the scientific and pedagogical achievements of Leonid Doskolovich.

\section{IPSI RAS}

In 1989 L. Doskolovich graduated with honors from the Kuibyshev aviation institute majoring in applied mathematics. After graduation, he started working as a software engineer at the Samara branch of the Central Design Bureau of Unique Instrumentation of the USSR Academy of Sciences (CDB UI). In 1993 the Samara branch of CDB UI was transformed into the Image Processing Systems Institute of RAS (IPSI RAS), and in 2016 IPSI RAS became a branch of the Federal Scientific Research Center "Crystallography and Photonics" of Russian Academy of Sciences. Since 1993 L. Doskolovich worked as a researcher, since 1996 - as a senior researcher, since 2002 - as a leading researcher, since 2013 - as a chief researcher, and since 2015 he has been working as the head of the laboratory of diffractive optics of IPSI RAS. 
L. Doskolovich`s scientific career developed as follows. In 1993 he defended his thesis "Methods of focusing laser radiation into a system of focal lines", program 01.04.01 "Physics experiment technique, physics of instruments, automation of physical research" at CDB UI of the USSR Academy of Sciences (Moscow), the candidate degree $(\mathrm{PhD})$ of physical and mathematical sciences was awarded to him in 1994. In 2001 he defended his Doctor of Science (DSc) thesis "Calculation of multi-order diffractive optical elements based on nonlinear phase transformation and optimization of the phase microrelief", program 01.04.05 "Optics" at Samara State Aerospace University named after academician S. Korolev (SSAU), the degree of Doctor of physical and mathematical sciences was awarded to him in 2002. The results of his dissertation research were published in the chapters of several monographs edited by V.A. Soifer (corresponding member of RAS) [1-4]. In 2015 for his scientific results in the field of diffractive optics and photonics L. Doskolovich was awarded the title of Professor of RAS.

Currently L. Doskolovich is the author and co-author of 276 scientific papers, including 10 monographs and 9 patents: in the database of RSCI there are 276 his publications and 2620 references (Hirsch index - 24), in the international database Scopus data - 154 Publication and 1117 references (Hirsch index - 18).

\section{Samara University}

L. Doskolovich combines his scientific activity with teaching. Since 1999 he has been working part-time at the department of technical cybernetics of Samara National Research University named after academician Sergey Korolev (until 2015 - Samara State Aerospace University named after academician S. Korolev (SSAU)). Starting with the position of an assistant and then successively occupying positions of a docent and a professor, in 2009 L. Doskolovich was awarded the title of professor at the Department of Technical Cybernetics. L. Doskolovich gives lectures on probability theory and mathematical statistics, modeling and synthesis of elements of photonics, synthesis of optical systems elements for students studying in the areas of applied mathematics and computer science and applied mathematics and physics. He supervises research work of bachelors, masters, and postgraduate students; he has advised six candidates of physical and mathematical sciences.

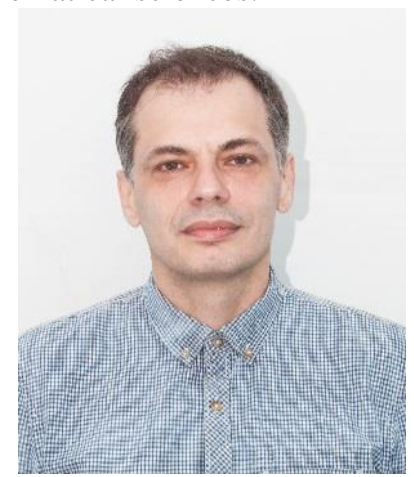

Fig. 1. Doctor of Physical and Mathematical Sciences, Professor L.L. Doskolovich 
L. Doskolovich has experience of scientific expertise: he is a member of three dissertation committees at SSAU, a reviewer of various foreign scientific journals, an expert of the Russian Science Foundation.

\section{The main scientific results}

The first scientific results were obtained by L. Doskolovich in the field of calculation of diffractive optical elements (DOEs). This scientific direction was headed by corresponding member of the Russian Academy of Sciences V.A. Soifer, who was the scientific adviser of L. Doskolovich`s candidate $(\mathrm{PhD})$ thesis. DOE are zone plates working in transmission or reflection and having complex boundaries and profile of zones. The working principle of DOEs is based on light diffraction on a thin phase microrelief [1-4]. The DOE design consists in the calculation the boundaries and zone profiles which ensure the desired properties of the optical element. One of the most interesting DOE classes are the so-called focusators of laser radiation. Focusators are DOE that focus laser radiation into thin curves or small areas, calculated in the geometrical optics approximation and having a regular structure of microrelief [1-8]. Focusators enable the formation of the desired spatial profile of laser radiation intensity along a given curve, which determines their wide application in various optical devices. Research in the field of designing the so-called multi-order focusators (the solution of the inverse diffraction problem) formed the basis of L. Doskolovich`s Candidate of Science dissertation. Multi-order focusators are DOEs that allow focusing into a set of curves in different diffraction orders [9-11]. The proposed DOEs combine a diffraction grating, which generates a set of diffraction orders, and a focusator into a line in a single element. Calculation of multi-order DOE is based on nonlinear transformation of the focusator phase function, with the transformation function corresponding to the phase function of a multi-order diffraction grating [12, 13]. A special case of this method is the method of calculating multifocal lenses for focusing into a set of points on the optical axis $[1,14,15]$, which later became widely used for calculating multifocal crystalline lenses [16-18]. These studies were continued in Doskolovich`s Doctor of Science dissertation, where he has developed a general analytical method for calculating multi-order focusators intended for focusing into a set of similar or differently shaped curves located in various planes perpendicular to the optical axis. In his dissertation, the method has also been generalized for the task of calculating spectral DOE, designed for separating and focusing radiation of different wavelengths into the areas of identical or different form [19-22]. In this case, DOE calculation was based on a non-linear transformation of DOE phase function according to the law of color separation grating [23]. On the basis of the method of phase nonlinear transformation L. Doskolovich has developed an original method for calculating the quantized DOE, using the approximation of the discrete complex transmission function of a quantized DOE by a truncated series of diffraction orders $[24,25]$. The developed method is equivalent by its computational cost to the gradient algorithms for calculating DOE with a continuous phase function. In his dissertation, the iterative methods for calculating multi-order diffraction gratings in the framework of electromagnetic theory were also proposed [26-29]. Later these methods have served as a basis for theoretical studies of extraordinary magneto-optical effects in 
diffraction gratings comprising a layer of magneto-optical material [30-42]. It has been shown that under resonant conditions the change of the transmission (reflection) coefficient of diffraction grating increases by 3-4 orders of magnitude when the layer material is magnetized, and the angle of rotation of the polarization plane increases by 1-2 orders. The discovered effects form the basis for the creation of new methods of ultrafast modulation of optical radiation by an external magnetic field. The developed theoretical basis for calculation and modeling of diffraction gratings was also used to calculate optical elements designed to steer the propagation of surface electromagnetic waves, in particular, of surface plasmon polaritons [43-56]. This result is of great interest for creating new data processing devices in the on-chip geometry, optical sensors, and near-field nanolithography systems.

Currently Doskolovich`s research interests mainly consist in the development and investigation of new nanophotonic devices for analog optical information processing. Ongoing studies are in line with technologies of silicon nanophotonics, aimed at creating a new generation of computer systems in which the light pulses will be used as information carriers instead of electrical signals. Doskolovich`s works theoretically prove the possibility of analog optical information processing and optical computing on the basis of resonant diffraction structures: diffraction gratings, Bragg multilayer structures, microresonators [57-71]. In the mentioned works, it is shown that these planar diffraction structures enable performing basic operations of spatio-temporal filtering, including spatial and temporal differentiation and integration of optical signals.

For many years, L. Doskolovich actively cooperated with several foreign companies (Fiat, Italy; Targetti, Beghelli and Plast-ottica companies, Italy; LG and Samsung, Korea) in the field of calculation and creation of lighting devices for different applications. The key and most difficult task in this field is to calculate the optical system of the lighting device from the condition of generating a given light intensity distribution. This task belongs to the class of inverse problems of nonimaging optics. Even in the case of only one surface and a point light source, this problem reduces to solving a complex nonlinear partial differential equation of the Monge-Ampere type, and its solution is very challenging. In the works of L. Doskolovich a wide class of methods is developed for solving the inverse problems of nonimaging optics and for calculating lighting devices for different applications [72-87]. The developed methods are widely used for the design of energy-efficient LED-based lighting systems.

\section{Conclusion}

In conclusion, I would like to wish Leonid Doskolovich talented students to continue and expand scientific research for development of new devices based on the achievements of diffractive optics and nanophotonics [88-90]!

\section{References}

1. Iterative Methods for Diffractive Optical Elements Computation / V. Soifer, V. Kotlyar, L. Doskolovich - Taylor \& Francis LTD, 1997, 244 p. 
2. Methods for Computer Design of Diffractive Optical Elements / V.A. Soifer, V.V. Kotlyar, N.L. Kazanskiy, L.L. Doskolovich, S.I. Kharitonov, S.N. Khonina, V.S. Pavelyev, R.V. Skidanov, A.V. Volkov, D.L. Golovashkin, V.S. Solovyev, G.V. Usplenyev; ed. V.A. Soifer - John Wiley \& Sons, Inc., New York, 2002, 765 p.

3. Computer Design of Diffractive Optics / D.L. Golovashkin, V.V. Kotlyar, V.A. Soifer, L.L. Doskolovich, N.L. Kazanskiy, V.S. Pavelyev, S.N. Khonina, R.V. Skidanov; ed. V.A. Soifer - Cambridge Inter. Scien. Pub. Ltd. \& Woodhead Pub. Ltd., 2012, 896 p.

4. Diffractive Nanophotonics / A.V. Gavrilov, D.L. Golovashkin, L.L. Doskolovich, P.N. Dyachenko, S.N. Khonina, V.V. Kotlyar, A.A. Kovalev, A.G. Nalimov, D.V. Nesterenko, V.S. Pavelyev, Y.O. Shuyupova, R.V. Skidanov, V.A. Soifer; ed. by V.A. Soifer, CRC Press, Taylor \& Francis Group, CISP, Boca Raton, 2014, 679p.

5. Golub MA, Doskolovich LL, Sisakyan IN, Soifer VA, Kharitonov SI. Diffractive corrections while focusing laser radiation into a line segment. Optics and Spectroscopy, 1991; 71(6): 1069-1073 [in Russian].

6. Doskolovich LL, Kazanskiy NL, Kharitonov SI, Usplenjev GV. Focusators for laserbranding. Optics and Lasers in Engineering, 1991; 15(5): 311-322. DOI: 10.1016/01438166(91)90018-O.

7. Doskolovich LL, Khonina SN, Kotlyar VV, Nikolsky IV, Soifer VA, Uspleniev GV. Focusators into a ring. Optical and Quantum Electronics, 1993; 25(11): 801-814.

8. Doskolovich LL, Kazanskiy NL, Kharitonov SI, Soifer VA. A method of designing diffractive optical elements focusing into plane areas. Journal of Modern Optics, 1996; 43(7): 1423-1433. DOI: 10.1080/09500349608232815.

9. Golub MA, Doskolovich LL, Soifer VA, Kharitonov SI. Diffraction approach to the synthesis of multifunctional phase elements. Optics and Spectroscopy, 1992; 73(1): 111-113.

10. Soifer VA, Doskolovich LL, Kazanskiy NL. Multifocal diffractive elements. Optical Engineering, 1994; 33(11): 3610-3615. DOI: 10.1117/12.179890.

11. Doskolovich LL, Golub MA, Kazanskiy NL, Khramov AG, Pavelyev VS, Seraphimovich PG, Soifer VA, Volotovskiy SG. Software on diffractive optics and computer generated holograms. Proceedings of SPIE, 1995; 2363: 278-284. DOI: 10.1117/12.199645.

12. Doskolovich LL, Soifer VA, Alessandretti G, Perlo P, Repetto P. Analytical initial approximation for multiorder binary grating design. Pure and Applied Optics: Journal of the European Optical Society Part A, 1994; 3(6): 921-930.

13. Doskolovich LL, Kotlyar VV, Soifer VA. Phase diffraction gratings with predetermined distribution of diffractive orders intensity. Technical Physics Letters, 1991; 17(21): 54-57 [in Russian].

14. Golub MA, Doskolovich LL, Kazanskiy NL, Kharitonov SI, Soifer VA. Computer generated diffractive multi-focal lens. Journal of Modern Optics, 1992; 39(6): 1245-1251. DOI: $10.1080 / 713823549$.

15. Doskolovich LL, Kazanskiy NL, Soifer VA, Tzaregorodtzev A.Ye. Analysis of quasiperiodic and geometric optical solutions of the problem of focusing into an axial segment. Optik - International Journal for Light and Electron Optics, 1995; 101(2): 37-41.

16. Osipov V, Doskolovich LL, Bezus EA, Cheng W, Gaidukeviciute A, Chichkov B. Fabrication of three-focal diffractive lenses by two-photon polymerization technique. Applied Physics A: Materials Science \& Processing, 2012; 107: 525-529.

17. Osipov V, Doskolovich LL, BezusEA, Drew T, Zhou K, Sawalha K, Swadener G, Wolffsohn JSW. Application of nanoimprinting technique for fabrication of trifocal diffractive lens with sine-like radial profile. Journal of Biomedical Optics, 2015; 20: 025008. 
18. Hinze U, El-Tamer A, Doskolovich LL, Bezus EA, Reiß S, Stolz H, Guthoff RF, Stachs O, Chichkov B. Additive manufacturing of a trifocal diffractive-refractive lens. Optics Communications, 2016; 372: 235-240.

19. Doskolovich LL. Diffractive optical elements computation for separating and focusing radiation of different wavelengths. Computer Optics, 1998; 8: 16-24 [in Russian].

20. Doskolovich LL, Petrova OI. Computation of spectral diffractive optical elements. Computer Optics, 1991; 19: 29-32 [in Russian].

21. Doskololovich LL, Repetto M. Design of does for focusing different wavelengths. Optical Memory and Neural Network, 2000; 9(3): 13-23.

22. Doskolovich LL, Kazanskiy NL, Soifer VA, Perlo P, Repetto P. Design of DOEs for wavelength division and focusing. Journal of Modern Optics, 2005; 52(6): 917-926. DOI: $10.1080 / 09500340512331313953$.

23. Doskolovich LL, Kazanskiy NL, Khonina SN, Skidanov RV, Heikkilä N, Siitonen S, Turunen J. Design and investigation of color separation diffraction gratings. Applied Optics, 2007; 46(15): 2825-2830. DOI: 10.1364/AO.46.002825.

24. Doskolovich LL, Perlo P, Repetto P, Petrova OI, Soifer VA. Direct 2D calculation of quantized DOE's on the basis of a continuous series approach. Journal of Modern Optics, 1997; 44(4): 685-696.

25. Doskolovich LL, Kazanskiy NL, Perlo P, Repetto P, Soifer VA. Direct two-dimensional calculation of binary DOEs using a non-binary series expression approach. International Journal of Optoelectronics, 1995; 10(4): 243-250.

26. Doskolovich LL, Kharitonov SI, Petrova OI, Soifer VA. A gradient method for design of varied - depth binary diffraction grating. Optics and Lasers in Engineering, 1998; 29(5): 249-259.

27. Doskolovich LL. Gradient method for multi-order binary dielectric gratings computation in the frame of electromagnetic theory. Computer Optics, 1998; 18: 82-91 [in Russian].

28. Doskolovich LL. Binary dielectric gratings and one-dimensional DOEs computation in the frame of electromagnetic theory. Computer Optics, 1991; 19: 21-28 [in Russian].

29. Doskololovich LL. Designing Binary Dielectric Gratings and 1-D DOEs Using the Electromagnetic Theory. Optical Memory and Neural Networks, 2000; 9(1): 1-12.

30. Belotelov VI, Doskolovich LL, Zvezdin AK. Extraordinary magneto-optical effects and transmission through metal-dielectric plasmonic systems. Physical Review Letters, 2007; 98: 077401.

31. Belotelov VI, Doskolovich LL, Kotov VA, Bezus EA, Bykov DA, Zvezdin AK. Magnetooptical effects in the metal-dielectric gratings Optics Communications, 2007. Vol. 278, №1. P.104-109.

32. Belotelov VI, Doskolovich LL, Kotov VA, Bezus EA, Bykov DA, Zvezdin AK. Giant magneto-optical orientational effect in plasmonic heterostructures. Optics Letters, 2009; 34(4): 398-400.

33. Belotelov VI, Bykov DA, Doskolovich LL, Kalish AN, Zvezdin AK. Optical properties of perforated metal-dielectric heterostructures magnetized in the plane. Physics of the Solid State, 2009; 51(8): 1656-1662.

34. Belotelov VI, Bykov DA, Doskolovich LL, Kalish AN, Zvezdin AK. Extraordinary transmission and giant magnetooptical transverse Kerr effect in plasmonic nanostructured films. J. Opt. Soc. Am. B, 2009; 26(8): 1594-1598.

35. Bykov DA, Doskolovich LL, Soifer VA Investigation of magneto-optical properties of dielectric gratings based on the analysis of parity and dispersion of eigenmodes. Computer Optics, 2009; 33(4): 384-392. 
36. Belotelov VI, Bykov DA, Doskolovich LL, Kalish AN, Zvezdin AK. Giant transversal Kerr effect in magneto-plasmonic heterostructures: The scattering-matrix method. Journal of Experimental and Theoretical Physics, 2010; 110(5): 816-824.

37. Bykov DA, Doskolovich LL. Extraordinary magneto-optical effect of transmitted wave phase change in periodic diffraction structures. Technical Physics Letters, 2010; 36(7): 595-598.

38. Bykov DA, Doskolovich LL. Magneto-optical resonances in periodic dielectric structures magnetized in plane. Journal of Modern Optics, 2009; 57(7): 1611-1618.

39. Bykov DA, Doskolovich LL, Soifer VA, Kazanskiy NL. Extraordinary magneto-optical effect of a change in the phase of diffraction orders in dielectric diffraction gratings. Journal of Experimental and Theoretical Physics, 2010; 111(6): 967-974. DOI: 10.1134/S1063776110120095.

40. Belotelov VI, Kreilkamp L, Akimov IA, Kalish AN, Bykov DA, Kasture S, Yallapragada VJ, Gopal AV, Grishin AM, Khartsev SI, Nur-E-Alam M, Vasiliev M, Doskolovich LL, Yakovlev DR, Alameh K, Zvezdin AK, Bayer M. Plasmon-mediated magneto-optical transparency. Nature Communications, 2013; 4: 2128.

41. Belotelov VI, Kreilkamp LE, Kalish AN, Akimov IA, Bykov DA, Kasture S, Yallapragada VJ, Gopal AV, Grishin AM, Khartsev SI, Nur-E-Alam M, Vasiliev M, Doskolovich LL, Yakovlev DR, Alameh K, Zvezdin AK, Bayer M. Magnetophotonic intensity effects in hybrid metal-dielectric structures. Phys. Rev. B, 2014; 89: 045118.

42. Bykov DA, Doskolovich LL. Controlling the surface plasmon excitation efficiency using dielectric magneto-optical cavity. Journal of Optics, 2014; 16: 085001.

43. Doskolovich LL, Kadomina EA, Kadomin II. Nanoscale photolithography by means of surface plasmon interference. J. Opt. A: Pure Appl. Opt., 2007; 9: 854-857.

44. Bezus EA, Bykov DA, Doskolovich LL, Kadomin II. Diffraction gratings for generating varying-period interference patterns of surface plasmons. J. Opt. A: Pure Appl. Opt., 2008; 10: 095204.

45. Bezus EA, Doskolovich LL, Kazanskiy NL, Soifer VA, Kharitonov SI. Design of diffractive lenses for focusing surface plasmons. Journal of Optics, 2010; 12(1): 015001. DOI: 10.1088/2040-8978/12/1/015001.

46. Bezus EA, Doskolovich LL. Grating-assisted generation of 2D surface plasmon interference patterns for nanoscale photolithography. Optics Communications, 2010; 283: 20202025.

47. Bezus EA, Doskolovich LL, Kazanskiy NL. Evanescent-wave interferometric nanoscale photolithography using guided-mode resonant gratings. Microelectronic Engineering, 2011; 88: 170-174. DOI: 10.1016/j.mee.2010.10.006.

48. Bezus EA, Doskolovich LL, Kazanskiy NL. Scattering suppression in plasmonic optics using a simple two-layer dielectric structure. Applied Physics Letters, 2011; 98(22): 221108. DOI: $10.1063 / 1.3597620$.

49. Bezus EA, Doskolovich LL, Kazanskiy NL. Interference pattern generation in evanescent electromagnetic waves for nanoscale lithography using waveguide diffraction gratings. $\begin{array}{llll}\text { Quantum } & \text { Electronics, } 2011 ; & \text { 41(8): }\end{array}$ 10.1070/QE2011v041n08ABEH014500.

50. Bezus EA, Doskolovich LL, Kazanskiy NL, Soifer VA. Scattering in elements of plasmon optics suppressed by two-layer dielectric structures. Technical Physics Letters, 2011; 37(12): 1191-1095. DOI: 10.1134/S1063785011120030.

51. Bezus EA, Doskolovich LL. Stable algorithm for the computation of the electromagnetic field distribution of eigenmodes of periodic diffraction structures. Journal of the Optical Society of America A, 2012; 29: 2307-2313. 
52. Bezus EA, Morozov AA, Volodkin BO, Tukmakov KN, Alferov SV, Doskolovich LL. Formation of high-frequency two-dimensional interference patterns of surface plasmon polaritons. JETP Letters, 2013; 98(6): 317-320.

53. Bezus EA, Doskolovich LL, Bykov DA, Soifer VA. Phase modulation of Bloch surface waves with the use of a diffraction microrelief at the boundary of a one-dimensional photonic crystal. JETP Letters, 2014; 99(2): 63-66.

54. Bezus EA, Doskolovich LL, Kazanskiy NL. Low-scattering surface plasmon refraction with isotropic materials. Optics Express, 2014; 22(11): 13547-13554. DOI: 10.1364/OE.22.013547.

55. Bezus EA, Bykov DA, Doskolovich LL. Antireflection layers in low-scattering plasmonic optics. Photonics and Nanostructures - Fundamentals and Applications, 2015; 13: 101-105.

56. Bezus EA, Doskolovich LL. Refraction and phase modulation of surface electromagnetic waves propagating at the boundary of a one-dimensional photonic crystal. Optics and Spectroscopy, 2015; 119(5): 784-788.

57. Bykov DA, Doskolovich LL, Soifer VA. Temporal differentiation of optical signals using resonant gratings. Optics Letters, 2011; 36(11): 3509-3511.

58. Bykov DA, Doskolovich LL, Soifer VA. Integration of optical pulses by resonant diffraction gratings. JETP Letters, 2012; 95(1): 6-9.

59. Bykov DA, Doskolovich LL, Soifer VA. On the ability of resonant diffraction gratings to differentiate a pulsed optical signal. Journal of Experimental and Theoretical Physics, 2012; 141(5): 724-730.

60. Bykov DA, Doskolovich LL, Soifer VA. Single-resonance diffraction gratings for timedomain pulse transformations: integration of optical signals. Journal of the Optical Society of America A, 2012; 29(8): 1734-1740.

61. Bykov DA, Doskolovich LL, Golovastikov NV, Soifer VA. Time-domain differentiation of optical pulses in reflection and in transmission using the same resonant grating. Journal of Optics, 2013; 15: 105703.

62. Golovastikov NV, Bykov DA, Doskolovich LL. Spatial integration of optical beams using multilayer Bragg structures. Computer Optics, 2014; 38(3): 372-376.

63. Doskolovich LL, Bykov DA, Bezus EA, Soifer VA. Spatial differentiation of optical beams using phase-shifted Bragg grating. Optics Letters, 2014; 39: 1278-1281.

64. Golovastikov NV, Bykov DA, Doskolovich LL. Resonant diffraction gratings for spatial differentiation of optical beams. Quantum Electronics, 2014; 44(10): 984-988.

65. Bykov DA, Doskolovich LL, Bezus EA, Soifer VA. Optical computation of the Laplace operator using phase-shifted Bragg grating. Optics Express, 2012; 22(21): 25084-25092.

66. Golovastikov NV, Bykov DA, Doskolovich LL, Bezus EA. Spatial optical integrator based on phase-shifted Bragg gratings. Optics Communications, 2015; 338: 457-460.

67. Golovastikov NV, Bykov DA, Doskolovich LL. Spatiotemporal pulse shaping using resonant diffraction gratings. Optics Letters, 2015; 40(15): 3492-3495.

68. Golovastikov NV, Bykov DA, Doskolovich LL, Soifer VA. Spatiotemporal optical pulse transformation by a resonant diffraction grating. Journal of Experimental and Theoretical Physics, 2015; 121(5): 899-907.

69. Emelyanov SV, Bykov DA, Golovastikov NV, Doskolovich LL, Soifer VA. Differentiating space-time optical signals using resonant nanophotonics structures. Doklady Physics, 2016; 61(1): 108-111.

70. Doskolovich LL, Bezus EA, Bykov DA. Phase-shifted Bragg gratings for Bloch surface waves. Optics Express, 2015; 23: 27034-27045.

71. Bezus EA, Doskolovich LL, Soifer VA. Near-wavelength diffraction gratings for surface plasmon polaritons. Optics Letters, 2015; 40: 4935-4938. 
72. Doskolovich LL, Kazanskiy NL, Soifer VA, Kharitonov SI, Perlo P. A DOE to form a line-shaped directivity diagram. Journal of Modern Optics, 2004; 51(13): 1999-2005. DOI: $10.1080 / 09500340408232507$.

73. Doskolovich LL, Kazanskiy NL, Kharitonov SI, Perlo P, Bernard S. Designing reflectors to generate a line-shaped directivity diagram. Journal of Modern Optics, 2005; 52(11): 1529-1536. DOI: 10.1080/09500340500058082.

74. Doskolovich LL, Kazanskiy NL, Bernard S. Designing a mirror to form a line-shaped directivity diagram. Journal of Modern Optics, 2007; 54(4): 589-597. DOI: 10.1080/0950034060102186.

75. Doskolovich LL, Borisova KV, Moiseev MA, Kazanskiy NL. Design of mirrors for generating prescribed continuous illuminance distributions on the basis of the supporting quadric method. Applied Optics, 2016; 55(4): 687-695. DOI: 10.1080/0950034060102186.

76. Moiseev MA, Byzov EV, Kravchenko SV, Doskolovich LL. Design of LED refractive optics with predetermined balance of ray deflection angles between inner and outer surfaces. Optics Express, 2015; 23(19): A1140-A1148.

77. Doskolovich LL, Moiseev MA, Bezus EA, Oliker V. On the use of the supporting quadric method in the problem of the light field eikonal calculation. Optics Express, 2015; 23(150): 19605-19617.

78. Moiseev MA, Kravchenko SV, Doskolovich LL. Design of efficient LED optics with two free-form surfaces. Optics Express, 2014; 22(7): A1926-A1935.

79. Doskolovich LL, Dmitriev AYu, Moiseev MA, Kazanskiy NL. Analytical design of refractive optical elements generating one-parameter intensity distributions. Journal of the Optical Society of America A, 2014; 31(11): 2538-2544.

80. Aslanov ER, Doskolovich LL, Moiseev MA, Bezus EA, Kazanskiy NL. Design of an optical element forming an axial line segment for efficient LED lighting systems. Optics Express, 2013; 21(23): 28651-28656. DOI: 10.1364/OE.21.028651.

81. Moiseev MA, Doskolovich LL, Borisova KV, Byzov EV. Fast and robust technique for design of axisymmetric TIR optics in case of an extended light source. Journal of Modern Optics 2013; 60(14): 1100-1106.

82. Moiseev MA, Doskolovich LL, Kazanskiy NL. Design of high-efficient freeform LED lens for illumination of elongated rectangular regions. Optics Express, 2011; 19(3): A225A233. DOI: 10.1364/OE.19.00A225.

83. Doskolovich LL, Dmitriev AYu, Bezus EA, Moiseev MA. Analytical design of freeform optical elements generating an arbitrary-shape curve. Applied Optics, 2013; 52(12): 25212526.

84. Aslanov E, Doskolovich LL, Moiseev MA. Thin LED collimator with free-form lens array for illumination applications. Applied Optics, 2012; 51(30): 7200-7205.

85. Doskolovich LL, Bezus EA, Moiseev MA, Bykov DA, Kazanskiy NL. Analytical sourcetarget mapping method for the design of freeform mirrors generating prescribed $2 \mathrm{D}$ intensity distributions. Optics Express, 2016; 24(10): 10962-10971. DOI: 10.1364/OE.24.010962.

86. Moiseev MA, Doskolovich LL. Design of TIR optics generating the prescribed irradiance distribution in the circle region. Journal of the Optical Society of America A, 2012; 29(9): 1758-1763.

87. Moiseev MA, Doskolovich LL. Design of refractive spline surface for generating required irradiance distribution with large angular dimension. Journal of Modern Optics, 2010; 57(7): 536-544.

88. Doskolovich LL, Bezus EA, Bykov DA. On the compensation of the diffraction orders overlap effect in the Offner spectrometer. Computer Optics, 2014; 38(4): 777-781. 
89. Kazanskiy NL, Kharitonov SI, Doskolovich LL, Pavelyev AB. Modeling of the operation of hyperspectrometer based on the Offner scheme. Computer Optics, 2015; 39(1): 70-76. DOI: 10.18287/0134-2452-2015-39-1-70-76.

90. Soifer VA, Kotlyar VV, Doskolovich LL. Diffractive optical elements in nanophotonics devices. Computer Optics, 2009; 33(4): 352-368. 